\title{
Development of an immobilization system for in situ micronutrients release
}

\author{
Philippe E. Ramos ${ }^{\text {a,* }}$, Miguel A. Cerqueira ${ }^{\text {b }}$, Michael T. Cook ${ }^{\mathrm{c}, \mathrm{d}}$, Ana I. Bourbon ${ }^{\text {a }}$, Vitaliy V. Khutoryanskiy ${ }^{\mathrm{d}}$, \\ Dimitris Charalampoulos ${ }^{\mathrm{e}}$, José A. Teixeira ${ }^{\mathrm{a}}$, António A. Vicente ${ }^{\mathrm{a}}$
}

a CEB - Centre of Biological Engineering, University of Minho, Campus de Gualtar, 4710-057 Braga, Portugal

b INL - International Iberian Nanotechnology Laboratory, Av. Mestre José Veiga s/n, 4715-330, Braga, Portugal

c School of Pharmacy, University of Hertfordshire, Hatfield AL10 9AB, UK

d School of Pharmacy, University of Reading, Reading RG6 6AD, UK

e Food and Nutritional Sciences, University of Reading, Reading RG6 6AD, UK

\section{A R T I C L E I N F O}

\section{Article history:}

Received 29 September 2016

Received in revised form 27 October 2016

Accepted 29 October 2016

Available online 01 November 2016

\section{Keywords:}

Coated microcapsules

Probiotics

Folate

Layer-by-layer

Microcapsules

\begin{abstract}
A B S T R A C T
An immobilization system constituted by coated microcapsules was developed aiming at immobilizing probiotic bacteria capable of producing folate and release it in a sustained manner into the intestine. Despite no probiotic folate-producers have been immobilized so far, the system has been developed with this goal and this work reports its stability and ability to release folate under gastro-intestinal conditions.

Microcapsules were made of alginate with three consecutive coatings of poly-L-lysine, sodium alginate and chitosan. Turbidity experiments showed a strong electrostatic interaction between these polymers. Fourier transform infrared spectroscopy (FTIR) and confocal analysis showed the stability of the coating materials when applied on the microcapsules, even after they were immersed in solutions simulating conditions in the stomach and small intestine (i.e. pH 2, $60 \mathrm{~min}$ and pH 7.2, $120 \mathrm{~min}$, respectively). Coated microcapsules have an average diameter size ranged from 20 and $40 \mu \mathrm{m}$, and swelled upon exposure to a neutral medium, without dissolution as showed by microscopy analyses. Release experiments proved the ability of the coated microcapsules to release folic acid, at different rates, depending on the applied coating. Release experiments showed that the first coating $(\varepsilon-P L L)$ is characterized by Fickian diffusion as the main release mechanism of folic acid. Fickian rate constant $\left(k_{F}\right)$ decreased with the number of consequent coatings, reflecting the decrease of predominance of Fick's behavior. Results showed that the developed coated microcapsules have suitable characteristics for encapsulation of folic acid aiming in situ release in the intestine.
\end{abstract}

(C) 2016 Elsevier Ltd. All rights reserved.

\section{Introduction}

Folate is a vitamin that occurs in a large number of forms, being all derived from folic acid (pteroylglutamic acid). However there are different forms of folate, being the most known folic acid and 5methyltetrahydrofolic acid (Belz \& Nau, 1998). Folate is part of some important metabolic pathways, such as methyl group biogenesis and synthesis of nucleotides, vitamins and amino acids (Jacob, 2000). According to the World Health Organization, folate deficiency is often associated with megaloblastic anemia, risk of low birthweight and placental abruption, risk of delivering preterm or small-for-gestational-age infants, risk of neural tube defects (NTD), depression or even dementia (de Benoist, 2008). The increased cancer risk is also reported in other studies (Stolzenberg-solomon et al., 2006). Folate fortification in food to maintain recommended daily intake (350 $\mu$ g for adults and $600 \mu \mathrm{g}$ for

\footnotetext{
* Corresponding author.

E-mail address: phramos@ceb.uminho.pt (P.E. Ramos).
}

pregnant women) has been used using the synthetic form of B9 vitamin, folic acid (European Food Safety Authority, 2014). However, folic acid has low bioavailability after food processing, storage and consumption, due to inefficient absorption (de Meer et al., 2005). More than that, folic acid has the capacity to mask, in an initial phase, vitamin B12 deficiency (Bailey \& Ayling, 2009; Morris \& Tangney, 2007), while also changing the activity of the hepatic dihydrofolate reductase enzyme (Bailey \& Ayling, 2009) and promoting cancer (Baggott, Oster, \& Tamura, 2012; Ulrich \& Potter, 2006). Considering all these reasons, food fortification by a natural folate form is highly recommended.

Some probiotic bacteria, such as Lactococcus lactis cremoris, Streptococcus thermophilus, Bifidobacterium lactis, B. breve, B. infantis and B. animalis are capable of producing large amounts of folate (Crittenden, Martinez, \& Playne, 2003; Sybesma, Starrenburg, Tijsseling, Hoefnagel, \& Hugenholtz, 2003). However, several factors limit probiotics' action in the human body, such as very weak resistance to gastro-intestinal conditions (Gueimonde \& Salminen, 2006) and low residence time in the intestine (Gardiner et al., 2004; Klingberg \& Budde, 2006). A 
possible solution to these problems mentioned above could be the encapsulation of folate-producers probiotics. Microcapsules are able to protect probiotics against high oxygen levels (Sunohara et al. 1995), food products (Tripathi \& Giri, 2014), freezing (Azizi et al., 2010; Sousa et al., 2013), and during the passage through the gastrointestinal tract (Sun \& Griffiths, 2000). Other limitation could be the direct contact of these bacteria with human gut, following reports mentioning concerns about the probiotics utilization in humans, such as: possible passage from the digestive tract to extra-intestinal sites, leading to infections (Butel, 2014), and an excessive immune stimulation by a direct contact of probiotics with the gut, that creates continuous immunological responses by human organism (Marteau \& Shanahan, 2003). However, a full and continuous encapsulation during the passage through the gastrointestinal system can provide other advantages such as the prevention of the interfacial activation, stimulation of production and excretion of secondary metabolites (Nazzaro et al., 2012).

Alginate is the most applied material in microcapsules formation due to its low price, ease of gelation and biocompatibility (Chen, Cao, Ferguson, Shu, \& Garg, 2012; Klein, Stock, \& Vorlop, 1983; Quong, Neufeld, Skjåk-Braek, \& Poncelet, 1998; Smidsrd \& Skjak-Brae, 1990; Tanaka \& Matsumura, 1983). Alginate is a polysaccharide extracted from brown algae and is composed of randomly 1-4 linked $\beta-D-$ mannuronic acid and $\alpha$-L-guluronic acid, M blocks and $G$ blocks, respectively (Smidsrd \& Skjak-Brae, 1990). The ratio between these two blocks ( $\mathrm{M} / \mathrm{G}$ ratio) leads to alginates with different characteristics when crosslinked with calcium, as only $\mathrm{G}$ blocks bind to calcium. This has a direct influence on the encapsulation efficiency, swelling and release kinetics. In microcapsule formation, alginates with a high $\mathrm{M} / \mathrm{G}$ ratio will be more permeable and will have a faster release of encapsulated compounds (Khanna, Moya, Opara, \& Brey, 2010). Alginates with a lower M/ $G$ ratio will form stronger structures, which are less permeable and more viscous due to the greater affinity of the $G$ blocks to calcium ions, compared to M blocks (Sarmento et al., 2007). Divalent calcium $\left(\mathrm{Ca}^{2+}\right)$ is the most commonly used ion to create alginate-based microcapsules, although other ions can also be used (Tam et al., 2011). There are different techniques for microencapsulation of probiotics, such as extrusion, spray drying, emulsification and coacervation (Rathore, Desai, Liew, Chan, \& Heng, 2013) but the production of microcapsules smaller than $100 \mu \mathrm{m}$ is less common in the literature. Microcapsules smaller than $100 \mu \mathrm{m}$ are important as they will not alter food texture (Adhikari, Mustapha, \& Grün, 2003) and thus their sensorial aspects. Nevertheless, depending on their hardness there are even works that refer microcapsules' sizes of $40 \mu \mathrm{m}$ that change food texture (Engelen, Van Der Bilt, Schipper, \& Bosman, 2005). Sheu and Marshall (1993) produced sodium alginate microcapsules smaller than $100 \mu \mathrm{m}$, by emulsion technique, as support to the alginate ionotropic gelation. Considering the small diameters of microcapsules below $100 \mu \mathrm{m}$, and that small capsules (below $200 \mu \mathrm{m}$ ) are less efficient for probiotics protection (Heidebach, Först, \& Kulozik, 2012), added barriers to protect microencapsulated probiotics have been developed, namely by using layer-bylayer (LbL) assembly. Electrostatic LbL coating involves the assembly of materials of opposite charge e.g. through exposure to alternating solutions of cationic and anionic polymers (Cook, Tzortzis, Khutoryanskiy, \& Charalampopoulos, 2013; Krasaekoopt, Bhandari, \& Deeth, 2006).

Different polysaccharides and proteins have been used to form LbL coatings (Tang, Wang, Podsiadlo, \& Kotov, 2006; Yan, Björnmalm, \& Caruso, 2014). Alginate|poly-L-lysine/alginate is a well-known combination of coatings which have been used on alginate based microcapsules. The interactions between these two polymers (alginate and poly-L-lysine (PLL)), in most cases leading to a LbL assembly, are based in the electrostatic interactions between the anionic groups $\mathrm{COO}^{-}$present in alginate and the cationic groups $\mathrm{NH}_{3}^{+}$present in PLL (Orive, Tam, Pedraz, \& Hallé, 2006). The electrostatic interactions of PLL are enhanced when the amount of M blocks present in alginate is higher, in others words, PLL cationic groups have more affinity for M blocks compared to the G blocks (Thu, Bruheim, Espevik, \& Skj, 1996).
Chitosan has been one of the most used materials to improve the protection of probiotics, e.g. as a coating on alginate microcapsules (Chávarri et al., 2010; Kamalian, Mirhosseini, Mustafa, \& Manap, 2014). Chitosan and alginate have also demonstrated mucoadhesive properties that are important to be used to increase the residence time of microcapsules in the gut (Sarmento et al., 2007; Takeuchi et al., 2005).

The objective of this work was developing an alginate-based probiotics encapsulation system smaller than $100 \mu \mathrm{m}$, with a rationally designed coating developed through LbL assembly. It has being developed aiming to host probiotic bacteria while being able to pass through the gastrointestinal system up to the point at which adhesion to the intestinal mucosa can be achieved, with the consequent exchange of nutrients and products (probiotic activation and a continuous encapsulation) in the intestine. This approach will increase the residence time of probiotics in the intestine and will avoid possible inflammatory responses or infections provoked by direct contact of probiotic bacteria with the intestinal mucosa. In this work will only be presented the development and characterization of the system and the results considering probiotics encapsulation and protection, as adhesion will not be explored. The developed system will be characterized in terms of size, swelling capacity, folate release behavior and the chemical interactions between the capsule and the coatings (FTIR analysis).

\section{Materials and methods}

\subsection{Materials}

Sodium alginates "Protanal CR 8223" (M/G ratio 65/35; 250-350 kDa) and "Protanal LFR5/60" (M/G ratio 30/70; 20-60 kDa) were purchased from FMC Biopolymer (Belgium). $\varepsilon$-poly-L-lysine ( $\varepsilon$-PLL) was purchased from Handary (Belgium - molecular weight - $30 \mathrm{kDa}$ ). Chitosan was obtained from Golden-Shell Biochemical Co. Ltd. (China - molecular weight - 5-10 kDa) with a degree of deacetylation of 95\%. Corn oil, Tween 80 (Panreac, Germany), fluorescein isothiocynate (FITC), rhodamine B isothiocynate (RITC), 1-ethyl-3-(-3-dimethylaminopropyl) carbodiimide hydrochloride (EDC), $N, N$-dimethylformamide and folic acid were purchased from Sigma (USA).

\subsection{Turbidity measurements}

All polymer solutions $(0.1 \% \mathrm{w} / \mathrm{v})$ were prepared in deionized water, except chitosan which was dissolved in a $1 \%(\mathrm{v} / \mathrm{v})$ lactic acid solution. A mixture of $5 \mathrm{~mL}$ of each solution was used, testing some combinations of biopolymers to be used as coating materials (sodium alginate CR 8223 with $\varepsilon$-PLL; $\varepsilon$-PLL with sodium alginate LFR5/60; sodium alginate LFR5/60 with chitosan). The $\mathrm{pH}$ of each mixture was adjusted with $0.2 \mathrm{~mol} \cdot \mathrm{L}^{-1}$ hydrogen chloride or $0.2 \mathrm{~mol} \cdot \mathrm{L}^{-1}$ sodium hydroxide solutions, in the range of 2 to 8 . In order to standardize the compounds concentration in all samples after $\mathrm{pH}$ adjustment, sodium chloride $\left(0.2 \mathrm{~mol} \cdot \mathrm{L}^{-1}\right)$ was added to obtain the same final volume in all experiments. Turbidity measurements were performed on a spectrophotometer at $400 \mathrm{~nm}$ (Jasco V560, Jasco Corporation, Japan).

\subsection{Microcapsules production}

Microcapsules were produced according to the method described by Sheu and Marshall (1993). These first tests were performed without bacteria to facilitate coated microcapsules characterization. The microcapsules were produced by dropwise addition of $20 \mathrm{~mL}$ sodium alginate (CR 8220), with a concentration of $1.5 \%$, into a $100 \mathrm{~mL}$ solution of vegetable oil with a concentration of $0.2 \%$ of Tween 80 . The mixture was then stirred for $10 \mathrm{~min}$ at $200 \mathrm{rpm}$. After this, a solution of $200 \mathrm{~mL}$ of calcium chloride $(0.05 \mathrm{M})$ was gently added during $20 \mathrm{~s}$ and the mixture stirred at $200 \mathrm{rpm}$ for $20 \mathrm{~min}$. After hardening, the solution was passed 
to a separatory funnel, where it remained for $30 \mathrm{~min}$. After this, the liquid (oil and water) was gently removed with a pipette. The residual volume containing the microcapsules was then filtered through a $100 \mu \mathrm{m}$ nylon filter using water to remove the residual oil. After filtration the microcapsules that passed through the filter (smaller than $100 \mu \mathrm{m}$ ) were centrifuged for $5 \mathrm{~min}$ at $600 \mathrm{rpm}$ (Centrifuge Heraeus Megafuge $1.0 \mathrm{R})$ and isolated.

\subsection{Layer-by-layer assembly - coated microcapsules production}

After production, the microcapsules were immersed in a $0.01 \% \varepsilon$-PLL solution $(10 \mathrm{~mL})$, with constant stirring of $200 \mathrm{rpm}$ for $15 \mathrm{~min}$, forming the coated microcapsules with a single coat. Then, the solution was centrifuged in the manner mentioned before. The next step was the immersion of the coated microcapsules (alginate|E-PLL) into a sodium alginate (LFR5/60) solution $(0.1 \%, 10 \mathrm{~mL}$ ) for $15 \mathrm{~min}$, followed by centrifugation (600 rpm, $10 \mathrm{~min}$ ). The recovered coated microcapsules (double coated) were then immersed into a chitosan solution $(0.01 \%, 10 \mathrm{~mL})$. After that, another centrifugation step separated the coated microcapsules from the chitosan solution.

\subsection{Fourier transform infrared (FTIR) spectroscopy}

In order to confirm the adhesion of the different coatings, FTIR analyses were carried out with a Perkin Elmer 16 PC spectrometer (Perkin Elmer, Boston, MA, USA) in the wavenumber region of 600$4000 \mathrm{~cm}^{-1}$ using 16 scans for each sample. The microcapsules and coated microcapsules were freeze-dried prior to FTIR measurements.

\subsection{Diameter measurement}

Diameter measurements were performed through microscopy with a $10 \times$ magnification (Olympus BX51). Images of the samples were taken and at least 200 capsules were measured with Image J software.

\subsection{Testing of microcapsules and coated microcapsules in different $\mathrm{pH}$ 's}

Microcapsules and coated microcapsules were immersed into a $10 \mathrm{~mL}$ solution of potassium chloride - hydrogen chloride $(\mathrm{pH} 2)$ for $1 \mathrm{~h}$, stirred at $100 \mathrm{rpm}$. Then, the solution was centrifuged and the microcapsules and coated microcapsules were put into a phosphate buffer saline (PBS) solution ( $\mathrm{pH} 7.2$ ), for $3 \mathrm{~h}$. Aliquots of $100 \mu \mathrm{L}$ were taken every $15 \mathrm{~min}$. During the PBS solution test, that has a duration of $3 \mathrm{~h}$, samples were taken every $45 \mathrm{~min}$. Each experiment was performed in triplicate. These experiments were performed in microcapsules and coated microcapsules with one coating ( $\varepsilon$-PLL), two coatings (previous coating and alginate) and with three coatings (previous coatings and chitosan). All these experiments were performed independently and in triplicate. For each sample, diameter measurements were performed.

\subsection{Compounds labeling}

Chitosan-[RITC] was prepared by mixing $100 \mathrm{~mL}$ of $1 \%$ chitosan with $50 \mathrm{mg}$ RITC and $20 \mathrm{mg}$ EDC at $4{ }^{\circ} \mathrm{C}$ for 1 day. Alginate-[FITC] was prepared by mixing $100 \mathrm{~mL}$ of $1.76 \%$ alginate with $10 \mathrm{mg}$ FITC and $20 \mathrm{mg}$ EDC at $4{ }^{\circ} \mathrm{C}$ for 1 day. The residual free dye was then dialyzed off (molecular weight cut-off 3500 Da; Cell-Sep. H1, Membrane Filtration products, USA) with double distilled water for 2 weeks (Chang, Lee, $\mathrm{Wu}$, Yang, \& Chien, 2012). To the FITC-labeled $\varepsilon$-PLL, $0.1 \%$ of a $\varepsilon$ PLL solution was dissolved in $0.2 \mathrm{M} \mathrm{NaHCO}_{3}$ buffer ( $\mathrm{pH} 9$ ) and $1.0 \mathrm{mg}$ $(0.0026 \mathrm{mmol})$ of FITC was dissolved in $\mathrm{N}, \mathrm{N}$-dimethylformamide. Both solutions were stirred overnight. The $\varepsilon$-PLL/FITC solution was purified by dialysis (molecular weight cut-off 1000 Da; Cell-Sep. H1, Membrane Filtration products, USA) and the compound was dried by freeze-drying for further utilization (Kleinberger, Burke, Dalnoki-Veress, \& Stöver, 2013).
2.9. Confocal microscopy analyses during the gastrointestinal $\mathrm{pH}$ simulation

The same media and conditions were used as mentioned in Section 2.7 but samples were taken at $5 \mathrm{~min}$ and $60 \mathrm{~min}$ in the potassium chloride - hydrogen chloride medium and at $5 \mathrm{~min}$ and $3 \mathrm{~h}$ in the PBS medium. All samples were analyzed by confocal microscopy (Nikon A1-R Confocal with Resonant Scanner). Independent experiments were performed where just the studied coating was labeled.

\subsection{Kinetic release profiles}

The release kinetics of folic acid was studied using an in vitro dialysis method. Folic acid was added to sodium alginate solution used for microcapsules' production, forming a solution with a concentration of folic acid of $2 \%$. The process of coated microcapsules' production was the same as mentioned before. Each production batch (10 $\mathrm{mL}$ volume) was divided in two different experiments. Each experiment had $5 \mathrm{~mL}$ of coated microcapsules that were introduced in a dialysis membrane (molecular weight cut-off $15 \mathrm{kDa}$, Cellu-Sep. H1, Membrane filtration products, USA), which was subsequently placed into $40 \mathrm{~mL}$ of PBS solution, under magnetic stirring, at $37^{\circ} \mathrm{C}$, with no exposure to light. At appropriate time intervals, $0.8 \mathrm{~mL}$ of supernatant were taken and fresh medium was replaced to keep the initial volume constant. The amount of folic acid released from the coated microcapsules was evaluated by measuring the absorbance at $309 \mathrm{~nm}$ (Elisa Biotech Synergy HT, Biotek, USA). Coated microcapsules were produced without folic acid and a release experiment was performed proving that no significant absorbance could be measured from the samples of that experiment.

All the tests were run at least in triplicate.

\subsection{Mathematical modeling}

Folic acid release profile from the coated microcapsules was evaluated using a kinetic model that accounts for both Fickian and Case II transport (linear superposition model - LSM) effects in hydrophilic matrices (Berens \& Hopfenberg, 1978b):

$M_{t .}=M_{F}+M_{R}$

where $M_{t}$ is the total mass released from the coated microcapsule, $M_{F}$ and $M_{R}$ are the contributions of the Fickian and relaxation processes, respectively, at time $t$.

The Fickian process is described by:

$M t, F=M \infty, F\left[1-\frac{6}{\pi^{2}} \sum_{n=1}^{\infty} \frac{1}{n^{2}} \exp \left(-n^{2} k_{F} t\right)\right]$

where

$K_{F}=\frac{4 \pi^{2} D}{d^{2}}$

$\mathrm{M}_{\infty, \mathrm{F}}$ is the compound release at equilibrium, $D$ is diffusion coefficient and $d$ is the capsule diameter.

As for polymer relaxation, it is driven by the swelling ability of the polymer and it is therefore related to the dissipation of stress induced by the entry of the penetrant and can be described as a distribution of relaxation times, each assuming a first order-type kinetic equation (Berens \& Hopfenberg, 1978a).

$M t, R=\sum_{i} M \infty, i[1-\exp (-K i, t)]$

where each $K_{i}$ is the respective relaxation rate constant and each $M_{\infty, i}$ represents the equilibrium sorption of the $i^{\text {th }}$ relaxation process. 
Substitution of equations (Eq. (2)) and (Eq. (4)) into equation (Eq. (1)) results in:

$$
\begin{aligned}
M t, F= & M \infty, F\left[1-\frac{6}{\pi^{2}} \sum_{n=1}^{\infty} \frac{1}{n^{2}} \exp \left(-n^{2} k_{F} t\right)\right] \\
& +\sum_{i} M \infty, R i[1-\exp (-K R i, t)]
\end{aligned}
$$

This "general" model can then be used to describe pure Fickian $\left(M_{t, F} \neq 0\right.$ and $\left.i=0\right)$; anomalous $\left(M_{t, F}\right.$ and $\left.i \neq 0\right)$ or Case II $\left(M_{t, F}=0\right.$ and $i \neq 0$ ) transports.

\subsection{Statistical analyses}

Statistical analyses were performed using the analyses of variance (ANOVA) procedure with SigmaPlot 11.0 software for windows, where a $p<0.05$ was considered to be statistically significant, on the diameter and turbidity measurements.

Eq. (5) was fitted to data by non-linear regression, using STATISTICA v7.0 (Statsoft. Inc., USA). The Levenberg-Marquardt algorithm for the least squares function minimization was applied. Adjusted determination coefficient $\left(R^{2}\right)$, squared root mean square error (RMSE) (i.e., the square root of the sum of the squared residues (SSE) divided by the regression degrees of freedom) and residuals inspection for randomness and normality were evaluated to determine regressions quality. Standardized Halved Width (SHW \%) (i.e. the ratio between 95\% Standard Error and the value of the estimate) was assessed to determine precision of the estimated parameters.

\section{Results and discussion}

The design of this system was made with the following criteria: the utilization of alginate CR 8223 , that has a $65 / 35$ ratio of the M/G blocks and a high molecular weight (app. $300 \mathrm{kDa}$ ) was meant to form a main core with high permeability due to its high molecular weight and high content of mannuronic residues (responsible for swelling and less affinity by calcium ions). The use of PLL, as the first coating, is expected to limit the continuous swelling of the alginate microcapsule that leads to erosion in the media containing monovalent ions and calcium sequestrants, while maintaining the permeability of the coated microcapsule. The subsequent coating, alginate LFR5/60, has a 30/60 M/G ratio and a low molecular weight. PLL has more affinity for M blocks than $\mathrm{G}$ blocks, which will promote electrostatic interactions between the first and the second coating (Thu et al., 1996). This second alginate coating will also work as a way to guarantee the interaction between PLL and chitosan (to be used in the third and last coating), maintaining the permeability of the system, and working as a bioadhesive material in the case of chitosan erosion. Chitosan used as the last coating has two main objectives: to protect the system (mainly the probiotics) in acidic environments and be responsible for the adhesion of coated microcapsules to the intestinal epithelium. The presented system, with the utilization of these specific materials and with that specific order, was never used before for the development of a coated microcapsule system. The combination of these materials creates a new coated microcapsule system that might have new functions and applications, such as the controlled release of micronutrients. Some of these characteristics will be studied and demonstrated in this work, others will be explored in a future work.

\subsection{Turbidity measurements}

Turbidity tests were performed to demonstrate that the coating materials effectively interact with each other via their charged groups, which are responsible by the electrostatic interactions established between them. The materials used to build the different coatings on the alginate microcapsules were: a) alginate CR 8223, negatively charged material at $\mathrm{pH}$ values above its $\mathrm{pKa}$; b) $\varepsilon$-PLL, positively charged material at $\mathrm{pH}$ values below its isoelectric point (pI); c) alginate LFR5/60, negatively charged material at $\mathrm{pH}$ values above its pKa (An et al., 2013; Cook, Tzortzis, Charalampopoulos, \& Khutoryanskiy, 2012); d) chitosan, positively charged material at $\mathrm{pH}$ values above its $\mathrm{pKa}$.

The turbidity of these four different solutions was measured at $\mathrm{pH}$ values between 2 and 8 , ensuring that the OD was never above 0.08 a.u. This confirms that any turbidity above this is the result of polyelectrolyte complex formation. The first experiment was performed with alginate CR 8223 and $\varepsilon$-PLL. The results showed a better interaction between the biopolymers at pH 5-6 (Fig. 1), as shown by higher OD values, being those statistically different for all experiments but not different at $\mathrm{pH} 4(p<0.05)$. The rest of the experiments are all statistically similar, but their minimal values of OD $(0.68 \pm 0.05)$ are considerably higher than the OD of the pure solutions, which indicates that electrostatic interactions occurred between these materials in all the $\mathrm{pH}$ range tested. These results can be justified considering that the $p K a$ of alginate is 3.3-3.7 ( $p$ Ka values of mannuronic acid and guluronic acid are 3.38 and 3.65, respectively (An et al., 2013)) and that the $p I$ of $\varepsilon$ PLL is of approximately 9 (Yoshida \& Nagasawa, 2003). The interactions observable at $\mathrm{pH} 2$ and 3 are possibly due to a remaining percentage of functional groups charged in alginate at these $\mathrm{pH}$ values $\mathrm{pH}$ at one unity below the pKa of alginate, the molecule will still have $10 \%$ of the functional groups charged (Po \& Senozan, 2001)).

The same experiment was performed with $\varepsilon$-PLL and alginate LFR5/ 60 solutions (Fig. 1), which correspond to the first and second coating of the microcapsule, respectively. The results showed that the strongest interactions between the two materials happen between $\mathrm{pH} 3$ and 8 , where no statistically significant differences are observed in that interval $(p<0.05)$. As mentioned before, the lower OD obtained at $\mathrm{pH} 2$ can be justified by a lower number of negatively charged functional groups in alginate, at this $\mathrm{pH}$. These results have a similar behavior when compared with the interactions between alginate CR8223 and $\varepsilon$-PLL and similar electrostatic interactions are present in this experiment. It is also important to mention that the observed OD values are higher, in general, when comparing the interaction of alginate LFR5/60 and alginate CR 8223 with $\varepsilon$-PLL. This fact can be justified by the strongest affinity of the amine groups of $\varepsilon$-PLL with the glucuronic residues (present in alginate) that are in a higher percentage in the alginate LFR5/60 (Thu et al., 1996).

The turbidity measurements performed with alginate LFR5/60 and chitosan showed that $\mathrm{pH}$, as before, influenced the results (Fig. 1). The pKa values of alginate and chitosan are 3.3-3.7 and 6.5 (Oliveira et al., 2014), respectively, which indicates that strong interactions are to be expected between the biopolymers at $\mathrm{pH}$ values between 3 and 5 , being those statistically different of the rest $(p<0.05)$ (as mentioned above, at $\mathrm{pH}$ values near the $\mathrm{pKa}$, half of the molecule's functional groups are charged). The results obtained between $\mathrm{pH} 6$ and 8 cannot be differentiated from a statistical point of view, which considering that those values are at the chitosan pKa or above that, means that chitosan is reducing the number of its functional groups with positive charge, and is starting to precipitate. In the tests at lower $\mathrm{pH}(\mathrm{pH} 2)$ the same is happening but with the alginate molecule. Electrostatic forces are present in the interaction of chitosan with alginate thus creating this significant turbidity (Chávarri et al., 2010). The interaction of these materials were also demonstrated in other works where a capsule constituted by alginate and PLL was produced (Constantinidis et al., 2007; Tam et al., 2005b). In other works were also proved the interaction of alginate and chitosan on the production and coating of a microcapsule (Shi, Alves, \& Mano, 2007; Zhao et al., 2007).

Turbidity results show that the materials used are able to interact, being a good indication of the formation of a LbL structure on the microcapsule. This evaluation is also important to demonstrate that the developed system is stable for $\mathrm{pH}$ values between 2 and 7 (i.e. stomach and intestine), which gives good perspectives to the utilization of this coated microcapsule as a gastrointestinal delivery system. After turbidity tests 


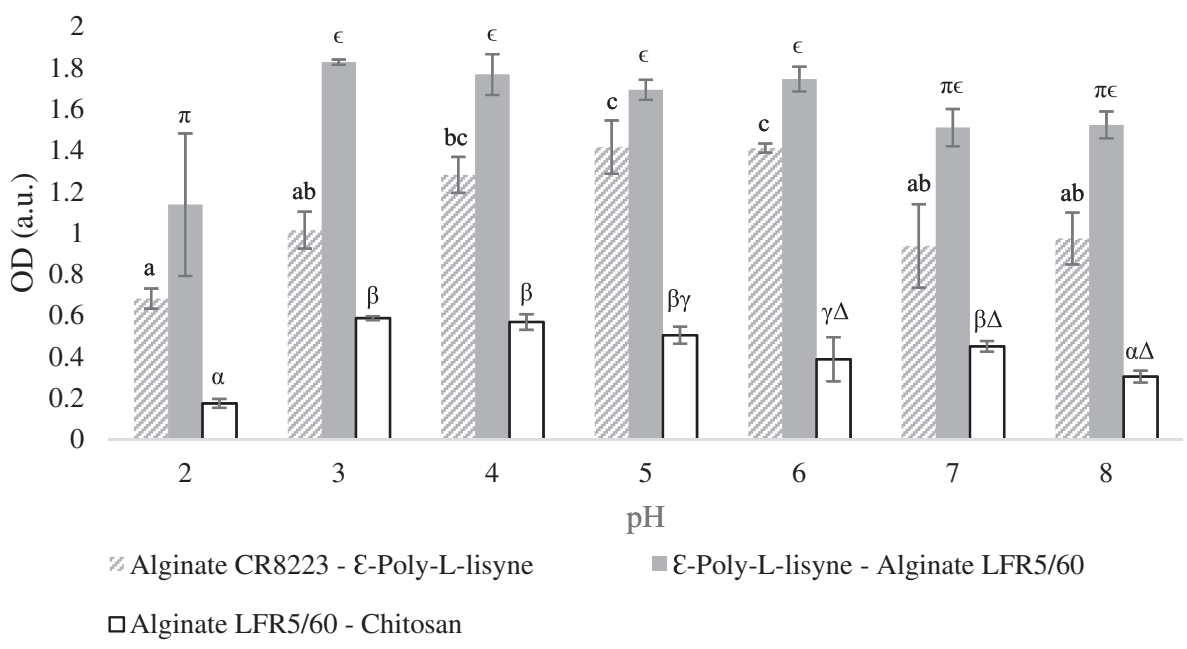

Fig. 1. Turbidity measurements for alginate CR 8223, $\varepsilon$-PLL, alginate LFR5/60 and chitosan. Different letters represent significantly different values ( $p<0.05$ ).

the concentrations of the solutions were optimized by $\zeta$-potential measurements in order to add successfully the different coatings to the microcapsule. These tests were conducted as described in Carneiro-daCunha et al. (2010) and the best solutions achieved were $0.01 \%$ for $\varepsilon$ PLL, $0.1 \%$ for alginate and $0.01 \%$ for chitosan.

\subsection{Size measurement}

Fig. 2 shows the diameter of the coated microcapsules through consecutive coating steps, demonstrating that coated microcapsules produced using this method are smaller than $100 \mu \mathrm{m}$, achieving that way the first goal of this work (microcapsules/coated microcapsules to protect bacteria that do not alter the texture/mouthfeel of the food product they are to be dispersed in). During sequential coating steps, the coated microcapsules' diameter decreased, comparing with microcapsules, phenomena that can be explained by the different behavior of these materials at different $\mathrm{pH}$ values. The alginate used in the microcapsules production has the capacity to swell through hydration that increased the microcapsules volume; this happens after the production in the final washing step with water. This was also reported by Sriamornsak, Thirawong, and Korkerd (2007) that tested a great number of alginates types and proved that alginate-based matrices are susceptible to hydrate at a neutral $\mathrm{pH}$. After generating the main core, the microcapsules were added to a solution of $\varepsilon$-PLL, creating the alginate $\mid \varepsilon$-PLL coated microcapsule (APM). This deposition decreased the diameter of the coated microcapsules in comparison with the alginate microcapsules, in a neutral $\mathrm{pH}$, due to the first coating formation. When APM were

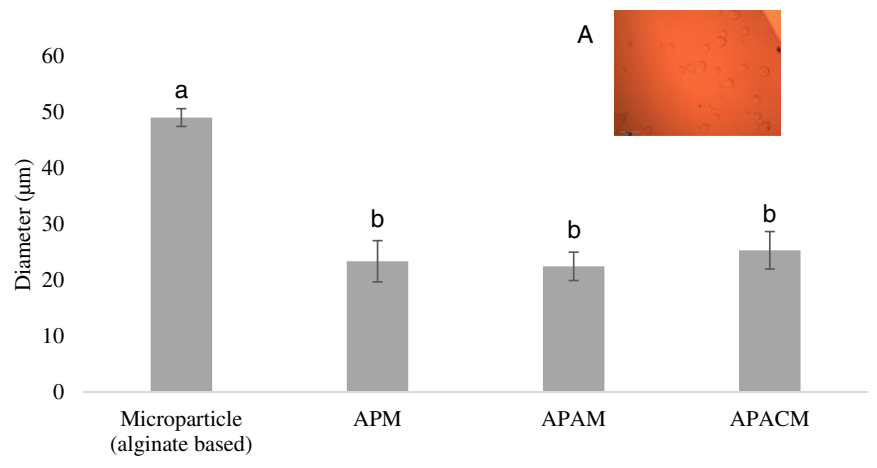

Fig. 2. Microcapsule and coated microcapsules diameter through the coatings deposition (capsules are immerged in water), A; and coated microcapsules' picture by microscope with a $10 \times$ lent (scale bar $150 \mu \mathrm{m})$, B. Different letters represent significantly different values $(p<0.05)$. put into water the swelling was reduced by the $\varepsilon$-PLL layer. This behavior can be explained by the capacity of this coating to limit the high hydration capacity, and consequent swelling capacity, of alginate microcapsules (Lawrie et al., 2007). The consequent layers adhesion creating the alginate $\mid \varepsilon$-PLL|alginate coated microcapsule (APAM) and alginate $\mid \varepsilon$-PLL|alginate|chitosan (APACM) did not change the diameter of the coated microcapsules, being the diameter results for the three coated microcapsules statistically equal and all different from the microcapsule diameter $(p<0.05)$.

\subsection{FTIR results}

FTIR results showed a significant similarity between the microcapsules spectra main peaks and those of alginate CR 8223 (Fig. 3), in both, the characteristic peaks of alginate at $3309 \mathrm{~cm}^{-1}$ (stretching vibrations of hydrogen-bonded OH groups), $1590 \mathrm{~cm}^{-1}$ and $1400 \mathrm{~cm}^{-1}$ (stretching vibrations of the $\mathrm{COO}^{-}$- Fig. 3(B)) are present (Shi et al., 2007; Shi, Alves, \& Mano, 2007; Tam et al., 2005a, 2005b). Just on microcapsules spectrum, two consequent peaks can be found at 2922 and $2852 \mathrm{~cm}^{-1}$ (Fig. 3(A)) and another one at $1743 \mathrm{~cm}^{-1}$ (Fig. 3(C)), both being the consequence of the presence of oil (Meng, Pan, Ding, \& Jiang, 2014; Vlachos et al., 2006).

Considering the spectra presented in Fig. 4, it is possible to identify that the oil spectra keep being present in all samples. The consequent coating adhesion showed that there are no significant modifications between the alginate microcapsules spectra and the coated microcapsules spectra. On the alginate microcapsules and APM spectra there are relevant differences such as the formation of two shoulders on both sides of peak 1590 (Fig. 4(A)), that correspond to the strong Amide I $\left(\sim 1637 \mathrm{~cm}^{-1}\right)$ and Amide II $\left(\sim 1552 \mathrm{~cm}^{-1}\right)$ OD bands of the $\varepsilon$-PLL (Tam et al., 2005a, 2005b). The presence of those peaks proves the presence of $\varepsilon$-PLL in the APM structure. The presence of alginate LFR5/60 is difficult to prove considering that its spectra is the same as the one of the initial alginate microcapsule, although it is possible to notice that the two shoulders presented in the last spectrum (APM spectra) characteristic of $\varepsilon$-PLL, disappear in the APAM spectrum which proves that the alginate coating was well succeed. Some characteristic peaks can be seen in Fig. 4(B) in the APACM spectrum, that are characteristic of the presence of chitosan, such as the one found at $1567 \mathrm{~cm}^{-1}$; this is a typical peak of the interaction between the negatively charged group $\mathrm{COO}^{-}$ of alginate and the positively charged groups $\mathrm{NH}_{3}^{+}$of chitosan. This peak is also responsible for the obstruction of the $1590 \mathrm{~cm}^{-1}$ alginate peak. This behavior can be found in other works dealing with the coating of alginate with chitosan (Shi et al., 2007). The $1729 \mathrm{~cm}^{-1}$ peak (Fig. $4(\mathrm{C})$ ) can be justified by the protonation of alginate, due to the contact 


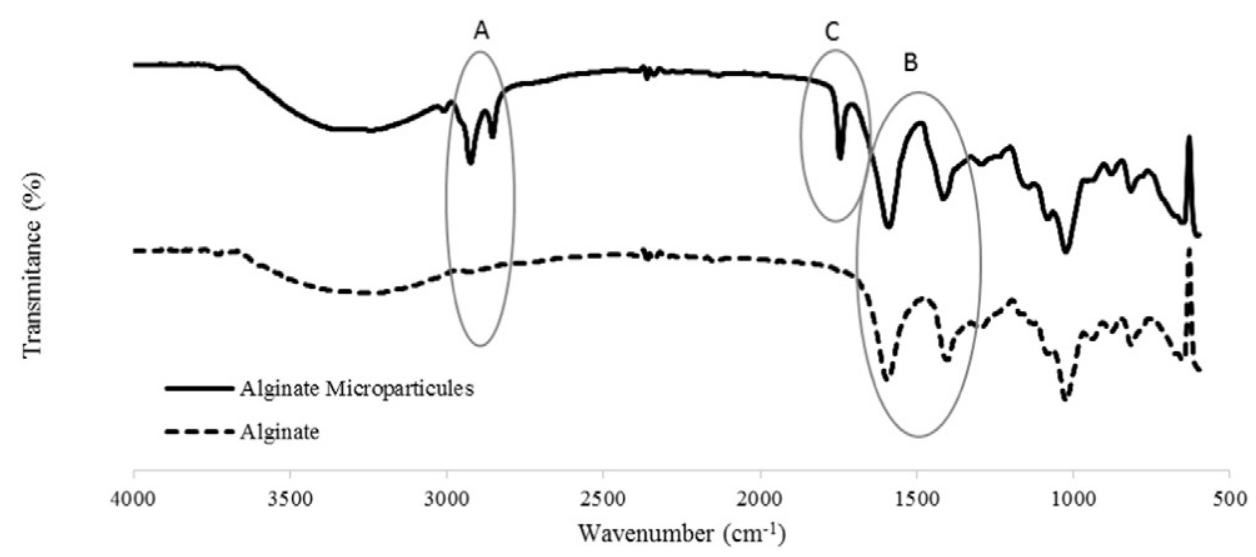

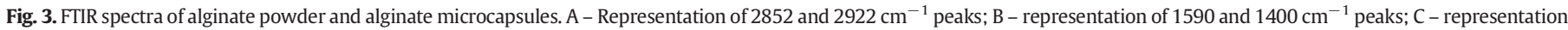
of the $1743 \mathrm{~cm}^{-1}$ peak.

of chitosan (dissolved in lactic acid) with alginate (Lawrie et al., 2007). These FTIR results show the successive adhesion of the different coatings.

\subsection{Confocal microscopy analyses}

The LbL assembly on alginate microcapsules was evaluated through confocal microscopy in order to show the adhesion of the materials to the main core microcapsule structure (Fig. 5). Alginate CR 8223, $\varepsilon$-PLL and alginate LFR5/60 were labeled with FITC and chitosan was labeled with rhodamine. To test the presence of each coating only one coating was labeled in each experiment, in order to differentiate all the coatings that were labeled with FITC. Confocal microscopy images showed the existence of the alginate-based microcapsules (Fig. 5a). Fig. 5b) shows the coated microcapsules labeled with $\varepsilon$-PLL, coated due to the electrostatic forces between $\mathrm{CO}_{2}^{-}$ groups, from alginate, and $\mathrm{NH}_{3}^{+}$from $\varepsilon$-PLL (Bystrick, Malovl, \& Sticzay, 1990). Fig. 5c) shows the adhesion of the second coating, composed of alginate LFR5/60. Fig. 5d) shows the presence of the subsequent chitosan layer on that of alginate LFR5/60 coated microcapsule, being its adhesion justified by electrostatic forces between the carboxyl groups of alginate and the amine groups of chitosan $\left(\mathrm{NH}_{2}^{+}\right.$) (Gazori et al., 2009; Sarmento et al., 2007). With these confocal images it was possible to prove the sequential adhesion of those different coatings to the main microcapsule structure.
3.5. Evaluation of structures into two different media that simulate gastrointestinal $\mathrm{pH}$

Tests were performed to determine the coated microcapsules' diameter in an acidic medium (potassium chloride - hydrogen chloride at $\mathrm{pH} 2,1 \mathrm{~h}$ ), simulating stomach $\mathrm{pH}$, and in a neutral $\mathrm{pH}$ medium (Phosphate Buffer Solution (PBS) - pH 7.2-3 h), simulating intestinal pH. Alginate microcapsules showed a good resistance to the potassium chloride - hydrogen chloride solution, as shown in Fig. 6. The structures presented an average diameter of $33.81 \pm 3.05 \mu \mathrm{m}$ in that solution.

In PBS the microcapsules had a different behavior. After 5 min they were starting to dissolve, making the measurement of their size impossible. This is due to exchange between the sodium ions present in the PBS solution and the calcium ions present in the alginate microcapsule, together with calcium sequestration by phosphates (Corona-Hernandez et al., 2013). This process generates an increase of repulsion between the $\mathrm{COO}^{-}$groups present in the alginate chains leading to a swelling of the structure (water intake), at an initial stage, which will later lead to a total collapse of the alginate microcapsule structure. Bajpai et al. (Bajpai \& Sharma, 2004) showed that alginate beads had the same behavior into a PBS solution, increasing their diameter during the first $3 \mathrm{~h}$ and leading to a total dissolution of the materials after that. Similar results were reported by Gao, Liu, Chen, and Zhang (2009).

To avoid the coated microcapsules' dissolution in the PBS medium, a coating was added on the alginate microcapsule. This coating will presumably lead to an increase of the structure's strength decreasing its

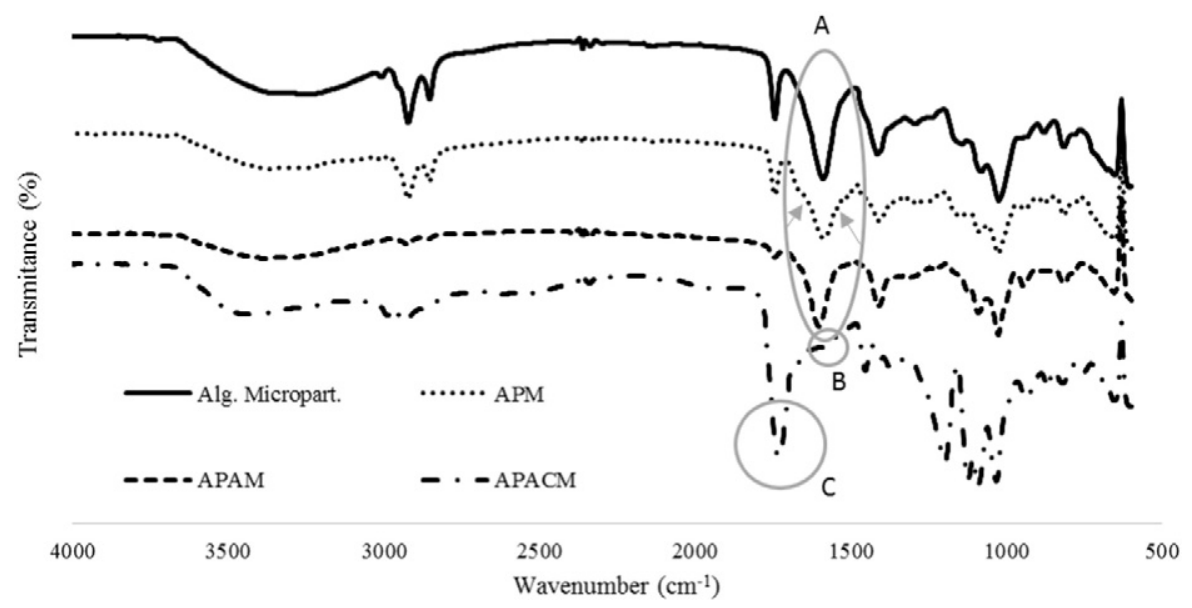

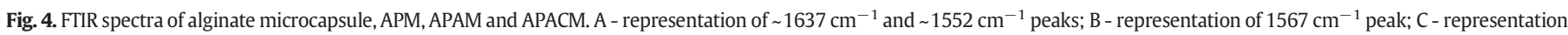
of $1729 \mathrm{~cm}^{-1}$ peak. 

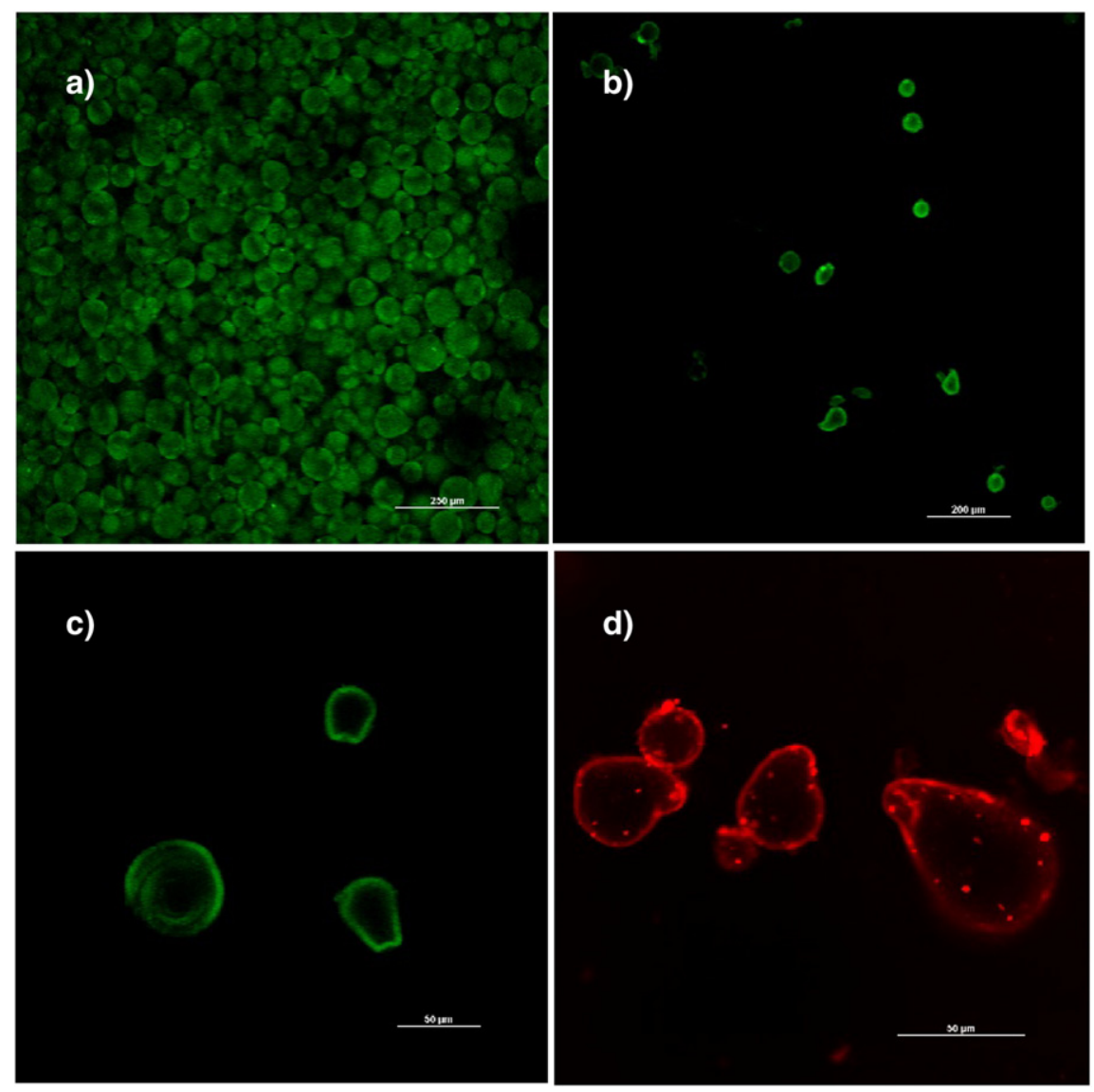

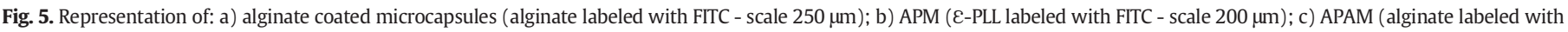
FITC - scale $50 \mu \mathrm{m}$ ); d) APACM (Chitosan labeled with Rhodamine - scale $50 \mu \mathrm{m}$ ).

swelling and thus avoiding dissolution. Some authors have shown that the utilization of $\varepsilon$-PLL as a coating on alginate microcapsules decreased the swelling degree of the alginate microstructure in a monovalent ions solution such as PBS (Capone et al., 2013; Tam et al., 2011). Fig. 7 shows the diameter of the coated microcapsules when immerged in potassium chloride - hydrogen chloride and PBS solutions. It is clear that a) there is no destruction of the coated microcapsules in the PBS solution; b) coated microcapsules' diameter is stable during the contact with the different media and there are no statistically significant differences between all diameters results in the potassium chloride - hydrogen chloride solution for all systems $(p<0.05)$ (average diameter of app. $20 \mu \mathrm{m})$ and the

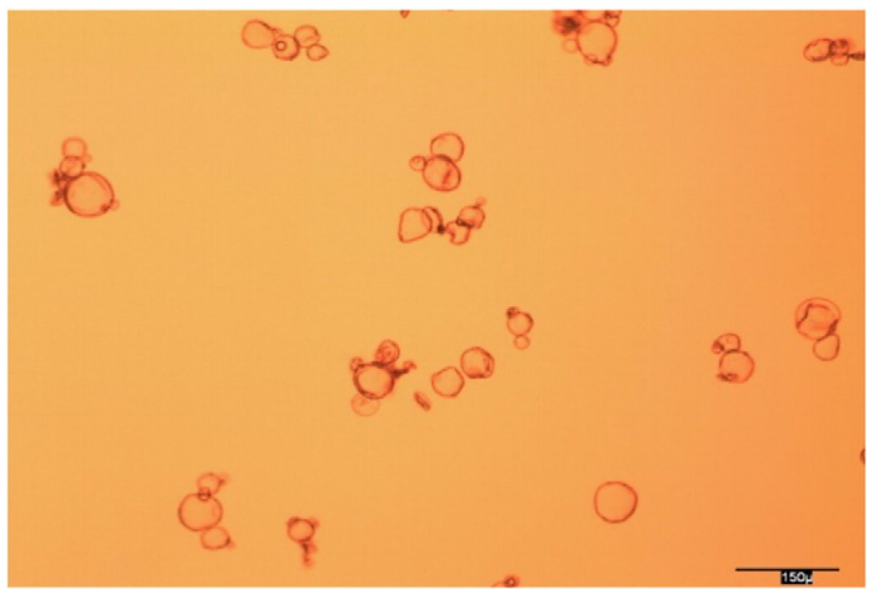

Fig. 6. Microscopy images of the microcapsules after $1 \mathrm{~h}$ into the acidic medium (scale $150 \mu \mathrm{m})$. same happens in the PBS solution, also for all systems $(p<0.05)$, being the average diameter around $40 \mu \mathrm{m}$; and c) there is a swelling degree of approximately 2-fold in diameter when coated microcapsules go from the potassium chloride - hydrogen chloride solution to the PBS solution, being that difference statistically significant. The $\varepsilon$-PLL coating showed that it was able to protect the structure against the ion exchange process, thus retarding its swelling.

Confocal microscopy was performed in order to evaluate the eventual loss of layers during the contact with the potassium chloride - hydrogen chloride and PBS media. As explained before, to test the presence of each coating only one coating was labeled in each experiment, in order to differentiate all the coatings that were labeled with FITC. Fig. 8 shows that the three different coatings were still over each other and attached to the main structure. Those results are in accordance with other published works (Cui, Goh, Kim, Choi, \& Lee, 2000; Kamalian et al., 2014; Krasaekoopt et al., 2006; Tam et al., 2011).

\subsection{Release kinetics of folic acid into phosphate buffer}

Mathematical modeling of transport phenomena is important for the design of carrier systems and of active compound carriers, since it may help predicting behavior in vivo. In this work, we studied the description of experimentally obtained data by the Linear Superimposition Model (LSM) (Eq. (5)). The mechanisms of folic acid release from coated microcapsules were evaluated at $37^{\circ} \mathrm{C}$ (temperature within the human body) and at $\mathrm{pH} 7$ ( $\mathrm{pH}$ of the small intestine).

In order to evaluate the physical mechanisms involved in folic acid release from coated microcapsules with different coatings it is important to use a model that successfully describes the individual contributions of the diffusion and the relaxation processes. The LSM was fitted to the experimental data: concerning the Fickian part of the model 


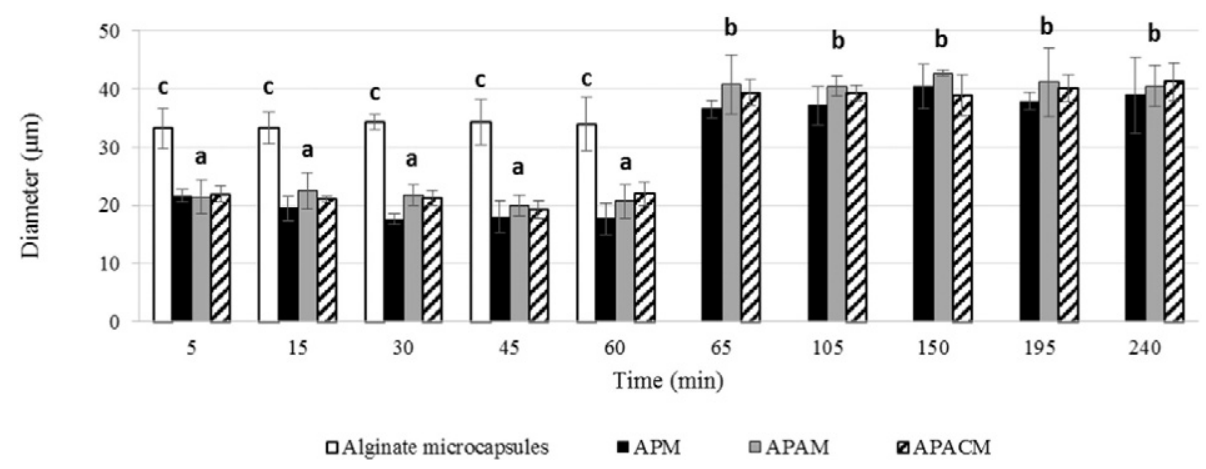

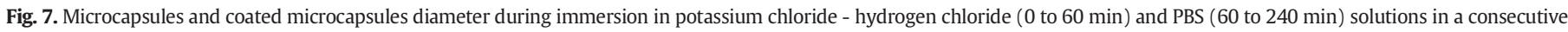
way, respectively. Different letters represent significantly different values $(p<0.05)$.

$\left(M_{F}\right.$, Eq. (2)) and the relaxation part of the model $\left(M_{R}\right.$, Eq. (4)). As reported by other works, this model assumes that the transport mechanism from coated microcapsules: i) can be due only to the concentration gradient and polymer relaxation had no effect on the transport mechanism (i.e. Fick's behavior; $i=0$ ); or ii) transport can be due to the sum of concentration gradient and to the relaxation of the polymer matrix $(i \neq 1)$ (Pinheiro, Bourbon, Vicente, \& Quintas, 2013).

Fig. 9 clearly shows the effect of applying different coatings on coated microcapsules in the folic acid release profile. For each coating applied on the coated microcapsule, LSM fitting curves showed a good description of the experimental data. This indicates that this transport mechanism cannot be described by Fick's diffusion of folic acid in the coated microcapsules alone, but is governed by both Fickian and Case
II transport. Also, it was observed that depending on the coating applied in the coated microcapsules, this system was governed by two or more relaxation processes.

Table 1 presents the regression analysis results of the LSM fitting, showing that this model adequately describes the experimental data with relatively good regression quality $\left(R^{2}>0.90\right)$ and that most parameters were estimated with good precision.

The fitting of LSM model to experimental data shows that the mechanisms involved in folic acid release are composed by Fick diffusion contribution $\left(M_{F}\right)$ and two or more relaxation processes $\left(M_{R}\right)$. The application of the first coating ( $\varepsilon-\mathrm{PLL}$ ) on the coated microcapsule suggests that Fick's diffusion is the main mechanism of folic acid release from the coated microcapsule. These results can be explained based on strong electrostatic interactions between alginate CR 8223 and $\varepsilon$ -

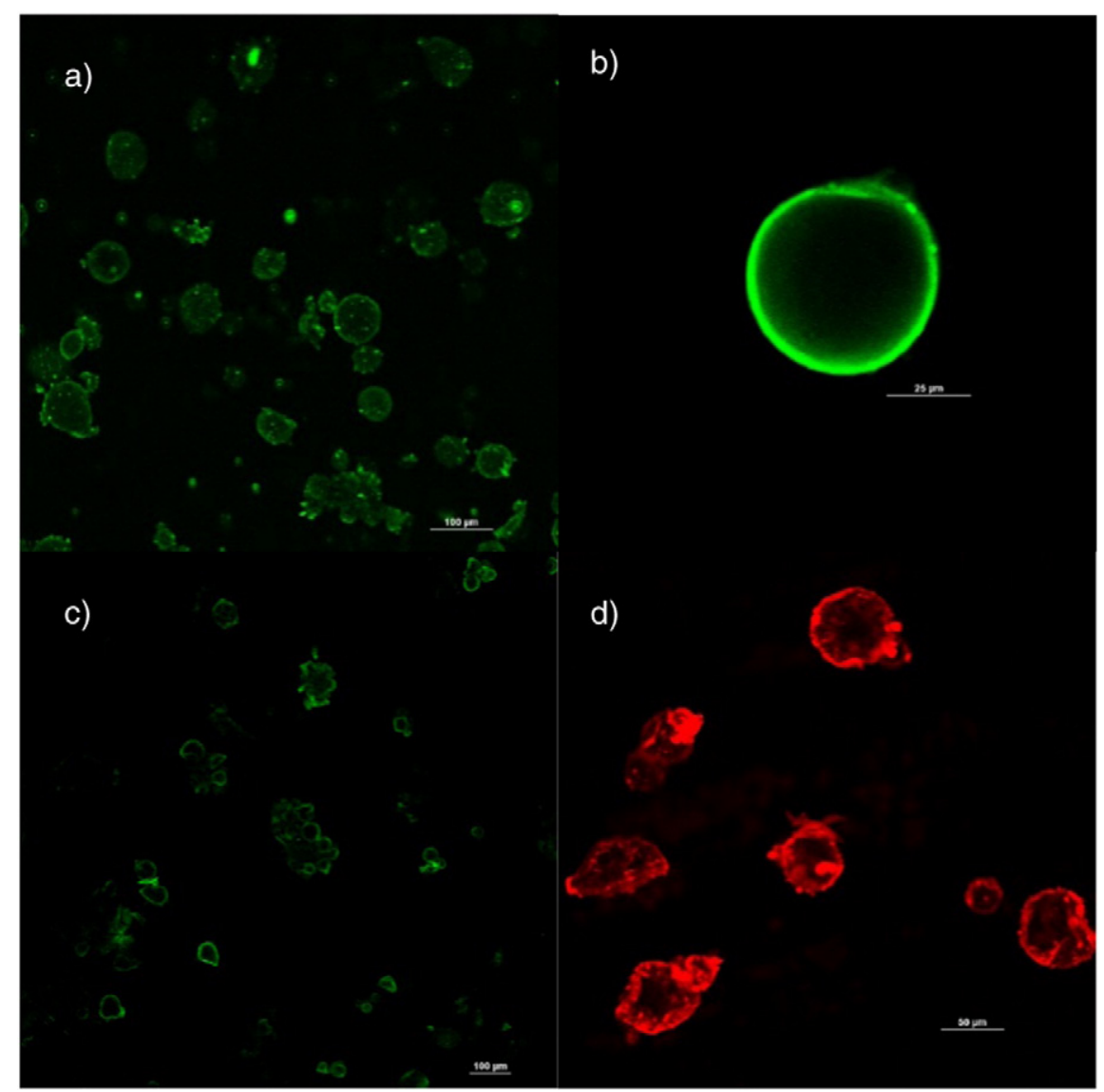

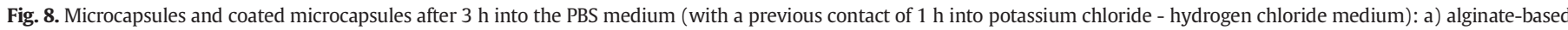

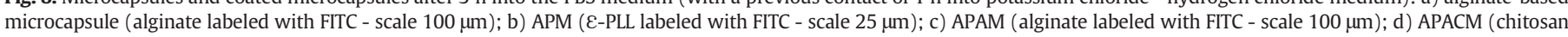
labeled with rhodamine - scale $100 \mu \mathrm{m}$ ). Independent experiments were performed where only the studied coating was labeled. 

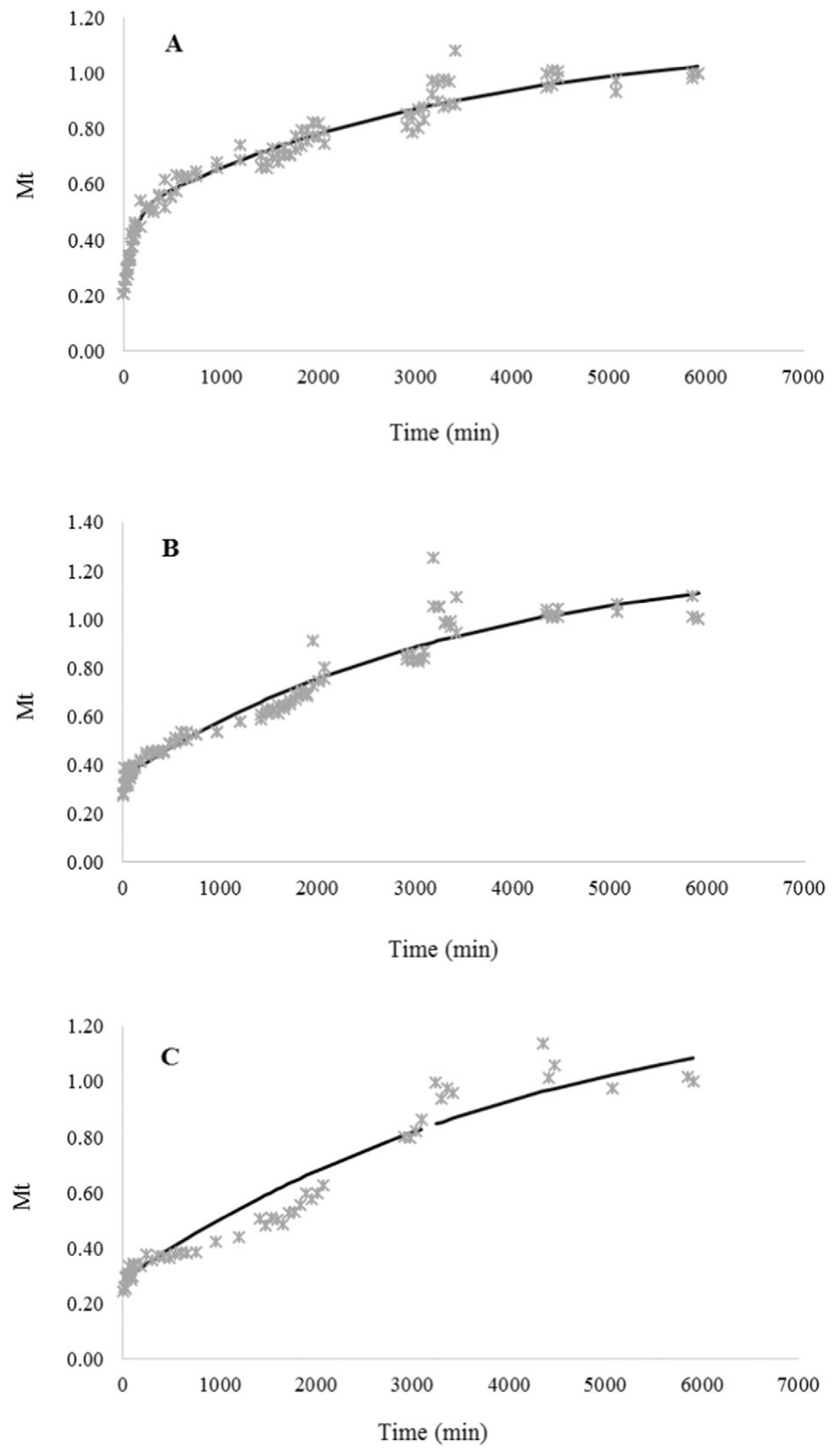

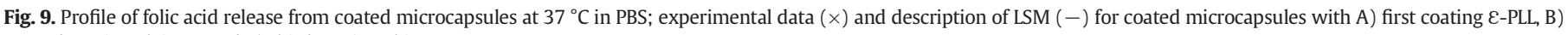
second coating alginate and C) third coating chitosan.

PLL at $\mathrm{pH} 7$ ( $\mathrm{pH}$ of PBS). As mentioned above (Section 3.1), at this $\mathrm{pH}$ the interaction between these materials is mainly due to the high affinity of the charges between the molecules (alginate - negative charge; $\varepsilon$ PLL - positive charge). Increasing the number of coatings on the coated microcapsule leads to a decrease of the Fick diffusion contribution and to the appearance of three relaxation steps. In fact, Fig. 10 shows that the anomalous transport considering two main relaxations $(i=2)$ was unable to predict the experimentally observed behavior and, hence, the physical mechanism of the transport phenomena involved for the coated microcapsule with the second and third coating was 
Table 1

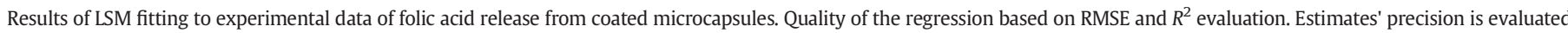
using the SHW\% (in parenthesis).

\begin{tabular}{|c|c|c|c|c|c|c|c|c|c|}
\hline Layer; $\mathrm{D}\left(\mathrm{m}^{2} \cdot \mathrm{min}^{-1}\right)$ & $M_{F}$ & $K_{F}$ & $M_{R 1}$ & $K_{R 1}$ & $M_{R 2}$ & $K_{R 2}$ & $M_{R 3}$ & $K_{R 3}$ & $\begin{array}{l}\text { RMS; } \\
\mathrm{R}^{2}\end{array}$ \\
\hline APM; $3.73 \times 10^{-13}$ & $\begin{array}{l}0.8135 \\
(17.95 \%)\end{array}$ & $\begin{array}{l}0.0003 \\
(29.76 \%)\end{array}$ & $\begin{array}{l}0.3274 \\
(1.74 \%)\end{array}$ & $\begin{array}{l}0.0003 \\
(33.39 \%)\end{array}$ & $\begin{array}{l}0.2925 \\
(19.78 \%)\end{array}$ & $\begin{array}{l}0.031 \\
(37.90 \%)\end{array}$ & - & - & $0.1473 ; 0.9739$ \\
\hline APAM; $1.256 \times 10^{-13}$ & $\begin{array}{l}0.7645 \\
(20.12 \%)\end{array}$ & $\begin{array}{l}0.0001 \\
(30.42 \%)\end{array}$ & $\begin{array}{l}0.2259 \\
(37.21 \%)\end{array}$ & $\begin{array}{l}0.0001 \\
(18.12 \%)\end{array}$ & $\begin{array}{l}0.0509 \\
(27.23 \%)\end{array}$ & $\begin{array}{l}0.029 \\
(24.32 \%)\end{array}$ & $\begin{array}{l}0.2326 \\
(30.25 \%)\end{array}$ & $\begin{array}{l}0.0002 \\
(50.44 \%)\end{array}$ & $0.3792 ; 0.9437$ \\
\hline AРACM; $1.256 \times 10^{-13}$ & $\begin{array}{l}0.7576 \\
(30.27 \%)\end{array}$ & $\begin{array}{l}0.0001 \\
(70.2 \%)\end{array}$ & $\begin{array}{l}0.2169 \\
(35.4 \%)\end{array}$ & $\begin{array}{l}0.0001 \\
(27.28 \%)\end{array}$ & $\begin{array}{l}0.2170 \\
(30.12 \%)\end{array}$ & $\begin{array}{l}0.0002 \\
(50.52 \%)\end{array}$ & $\begin{array}{l}0.1169 \\
(27.32 \%)\end{array}$ & $\begin{array}{l}0.0002 \\
(76.98 \%)\end{array}$ & $0.6473 ; 0.9093$ \\
\hline
\end{tabular}

$D$ - diffusion coefficient; $M_{F}$ - Fick diffusion contribution; $M_{R}$ - relaxation processes contribution; $K_{F}$ - Fickian rate constant; $K_{R}$ - relaxation rate constant.

changed. This reflects that with these two last coatings the structure is more unstable, which means that the electrostatic interactions between alginate CR $8223 \mid \varepsilon$-PLL|alginate LFR5/60 and alginate CR 8223|E-PLL| alginate LFR5/60|chitosan are weaker. This leads to the loosening of coated microcapsule' structure and promotes the release of folic acid due to polymer relaxation at different times. Also the relaxation rate constant $\left(k_{R}\right)$ decreased with the number of coatings, supporting this hypothesis. The rate at which folic acid molecules pass though the coated microcapsule layers decreases with the increase of the number of layers in the structure. Fickian rate constant $\left(k_{F}\right)$ also decreased with the number of coatings, reflecting the decrease of predominance of Fickian behavior.

The diffusion coefficient $(D)$ was estimated based on Eq. (4) and it is possible to observe that this parameter was influenced by the composition of the coatings on the coated microcapsule. The application of a second coating decreases $D$ from $3.73 \times 10^{-13}$ to $1.256 \times 10^{-13} \mathrm{~m}^{2} \cdot \mathrm{min}^{-1}$ and this last value remained constant for the third coating. These results suggest that the application of the second coating led to a slow, limiting step of the release of folic acid. This fact can also be explained by the utilization of two different alginates: the alginate used for the
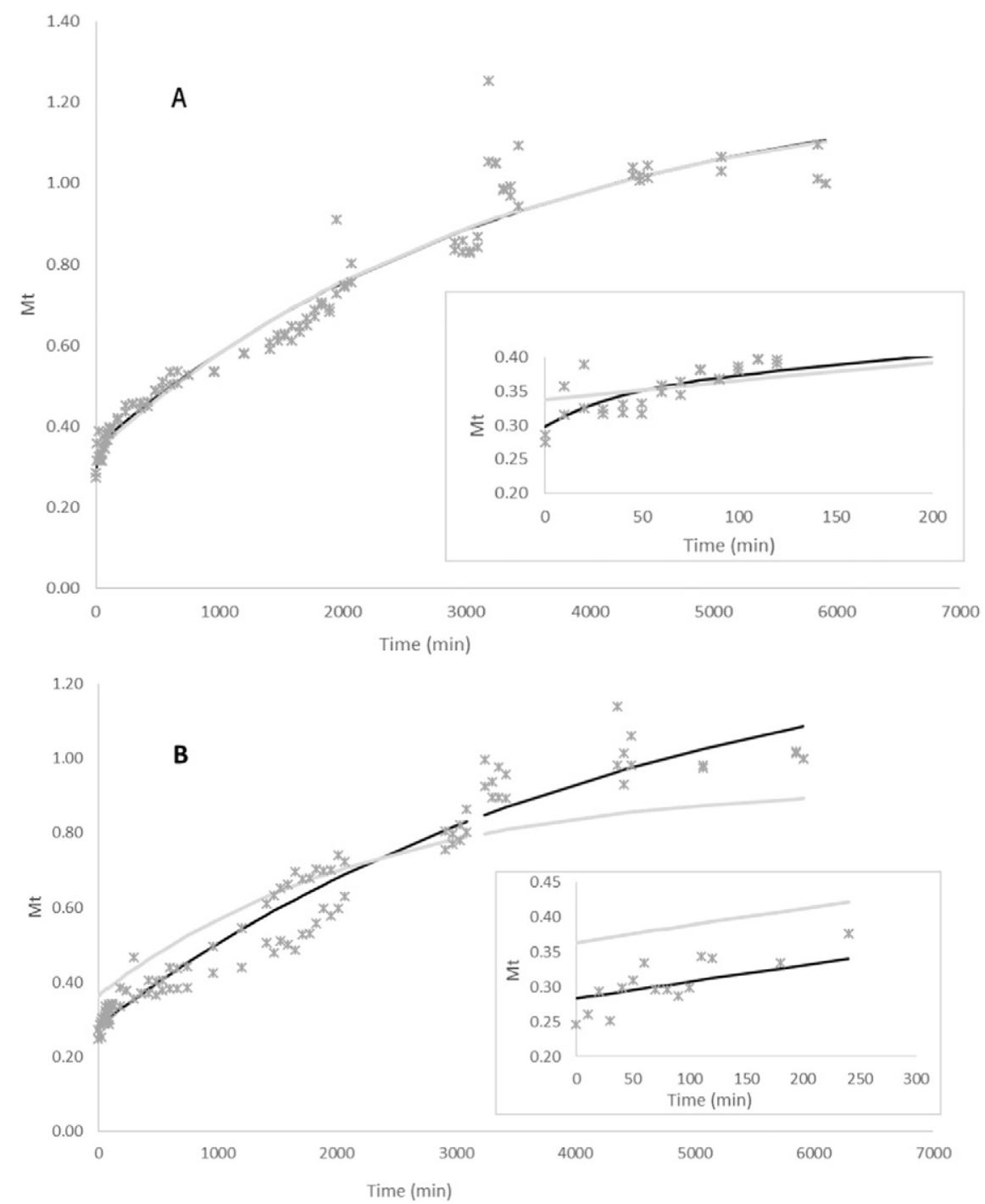

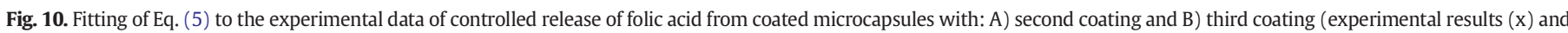
model-generated values for $i=2(-)$ and $i=3(-))$. Inset shows the detail of the model fitting to the initial experimental data. 
microcapsule production is more permeable, with a higher swelling capacity, while the one used as the second coating is more stable, with more $G$ residues (more connection points leading to a stronger adhesion to the adjacent layers), being these characteristics the main differences of these two alginates (Draget \& Taylor, 2011). Similar results in the release of folic acid from alginate-based capsules can be found in other works (Madziva, Kailasapathy, \& Phillips, 2005; Pérez-Masiá et al., 2015).

\section{Conclusions}

This work showed that it is possible to build coated microcapsules with three coatings ( $\varepsilon$-PLL, alginate and chitosan) with a good stability at different $\mathrm{pH}$ values. This allowed us to foresee that this coated microcapsule may have a good performance in probiotic protection under GIT conditions. The coated microcapsule has an average diameter smaller than $100 \mu \mathrm{m}$, thus being not detected in the mouth. Results also showed that its porosity will increase at neutral $\mathrm{pH}$, allowing an increased exchange of nutrients and products e.g. between encapsulated cells and the intestinal medium, although further tests need to be done to show this. According to the folic acid release experiments it was proved that this coated microcapsule is permeable to folic acid, even when three coatings are applied on it, although it was also shown that the increase of the number of coatings decreases the folic acid diffusivity through capsules.

\section{Acknowledgments}

The authors Philippe E. Ramos and Ana I. Bourbon, are recipient of fellowships from the Fundacão para a Ciência e Tecnologia, POPH-QREN and FSE (FCT, Portugal) through grants, SFRH/BD/80800/2012, SFRH/BD/73178/ 2010, respectively. The authors thank the FCT Strategic ProjectPEst-OE/EQB/ LA0023/2013 and the project "BioInd-Biotechnology and Bioengineering for improved Industrial and Agro-Food processes", REF. NORTE-07-0124FEDER-000028 co-funded by the Programa Operacional Regional do Norte (ON.2-O Novo Norte), QREN, FEDER. The authors would like to acknowledge to Graham Luke from Hopkins and Philip Lyle Microscopy Facilities (University of Reading) for assistance on confocal analysis. The authors also thank COST FA1001 and the European Network for Gastrointestinal Health Research (ENGIHR).

\section{References}

Adhikari, K., Mustapha, A., \& Grün, I. U. (2003). Survival and metabolic activity of microencapsulated bifidobacterium longum in stirred yogurt. Food Microbiology and Safety, 68(1), 275-280.

An, B., Son, H., Chung, J., Choi, J. W., Lee, S. H., \& Hong, S. W. (2013). Calcium and hydrogen effects during sorption of copper onto an alginate-based ion exchanger: Batch and fixed-bed column studies. Chemical Engineering Journal, 232, 51-58. http://dx.doi. org/10.1016/j.cej.2013.07.079.

Baggott, J. E., Oster, R. A., \& Tamura, T. (2012). Meta-analysis of cancer risk in folic acid supplementation trials. Cancer Epidemiology, 36(1), 78-81 (http://doi.org/10.1016/j. canep.2011.05.003)

Bailey, S. W., \& Ayling, J. E. (2009). The extremely slow and variable activity of dihydrofolate reductase in human liver and its implications for high folic acid intake. Proceedings of the National Academy of Sciences of the United States of America, 106(36), 15424-15429 (http://doi.org/10.1073/pnas.0902072106).

Bajpai, S. K., \& Sharma, S. (2004). Investigation of swelling/degradation behaviour of alginate beads crosslinked with $\mathrm{Ca}^{2+}$ and $\mathrm{Ba}^{2+}$ ions. Reactive and Functional Polymers, 59(2), 129-140 (http://doi.org/10.1016/j.reactfunctpolym.2004.01.002).

Belz, S., \& Nau, H. (1998). Determination of folate patterns in mouse plasma, erythrocytes, and embryos by HPLC coupled with a microbiological assay. Analytical Biochemistry, $166,157-166$.

Butel, M. -J. (2014). Probiotics, gut microbiota and health. Médecine et Maladies Infectieuses, 44(1), 1-8 (http://doi.org/10.1016/j.medmal.2013.10.002).

Bystrick, S., Malovl, A., \& Sticzay, T. (1990). Interaction of alginates and pectins with cationic polypeptides. Carbohydrate Polymers, 13, 283-294.

Capone, S. H., Dufresne, M., Rechel, M., Fleury, M. -J., Salsac, A. -V., Paullier, P., ... Legallais, C. (2013). Impact of alginate composition: From bead mechanical properties to encapsulated HepG2/C3A cell activities for in vivo implantation. PloS One, 8(4), e62032 (http://doi.org/10.1371/journal.pone.0062032).
Carneiro-da-Cunha, M. G., Cerqueira, M. A., Souza, B. W. S., Carvalho, S., Quintas, M. A. C., Teixeira, J. A., \& Vicente, A. A. (2010). Physical and thermal properties of a chitosan/ alginate nanolayered PET film. Carbohydrate Polymers, 82(1), 153-159 (http://doi. org/10.1016/j.carbpol.2010.04.043).

Chang, J. -J., Lee, Y. -H., Wu, M. -H., Yang, M. -C., \& Chien, C. -T. (2012). Preparation of electrospun alginate fibers with chitosan sheath. Carbohydrate Polymers, 87(3), 2357-2361 (http://doi.org/10.1016/j.carbpol.2011.10.054).

Chávarri, M. Marañón, I., Ares, R. Ibáñez, F. C. Marzo, F \& Villarán, M. D. C. (2010). Microencapsulation of a probiotic and prebiotic in alginate-chitosan capsules improves survival in simulated gastro-intestinal conditions. International Journal of Food Microbiology, 142(1-2), 185-189 (http://doi.org/10.1016/j.ijfoodmicro.2010.06.022).

Chen, S., Cao, Y., Ferguson, L. R., Shu, Q., \& Garg, S. (2012). Evaluation of mucoadhesive coatings of chitosan and thiolated chitosan for the colonic delivery of microencapsulated probiotic bacteria. Journal of Microencapsulation, 30(May 2012), 1-13 (http:// doi.org/10.3109/02652048.2012.700959).

Constantinidis, I., Grant, S. C., Celper, S., Gauffin-Holmberg, I., Agering, K., Oca-Cossio, J. a., ... Blackband, S. J. (2007). Non-invasive evaluation of alginate/poly-L-lysine/alginate microcapsules by magnetic resonance microscopy. Biomaterials, 28, 2438-2445 (http://doi.org/10.1016/j.biomaterials.2007.01.012).

Cook, M. T., Tzortzis, G., Charalampopoulos, D., \& Khutoryanskiy, V. V. (2012). Microencapsulation of probiotics for gastrointestinal delivery. Journal of Controlled Release: Official Journal of the Controlled Release Society, 162(1), 56-67 (http://doi.org/10. 1016/j.jconrel.2012.06.003).

Cook, M. T., Tzortzis, G., Khutoryanskiy, V. V., \& Charalampopoulos, D. (2013). Layer-bylayer coating of alginate matrices with chitosan-alginate for the improved survival and targeted delivery of probiotic bacteria after oral administration. Journal of Materials Chemistry B, 1(1), 52 (http://doi.org/10.1039/c2tb00126h).

Corona-Hernandez, R. I., Álvarez-Parrilla, E., Lizardi-Mendoza, J., Islas-Rubio, A. R., de la Rosa, L. A., \& Wall-Medrano, A. (2013). Structural stability and viability of microencapsulated probiotic bacteria: A review. Comprehensive Reviews in Food Science and Food Safety, 12(6), 614-628 (http://doi.org/10.1111/1541-4337.12030).

Crittenden, R. G., Martinez, N. R., \& Playne, M. J. (2003). Synthesis and utilisation of folate by yoghurt starter cultures and probiotic bacteria. International Journal of Food Microbiology, 80(3), 217-222 Retrieved from. (http://www.ncbi.nlm.nih.gov/ pubmed/12423923)

Cui, J. H., Goh, J. S., Kim, P. H., Choi, S. H., \& Lee, B. J. (2000). Survival and stability of bifidobacteria loaded in alginate poly-L-lysine microparticles. International Journal of Pharmaceutics, 210(1-2), 51-59 Retrieved from. (http://www.ncbi.nlm.nih.gov/ pubmed/11163987)

de Benoist, B. (2008). Conclusions of a WHO technical consultation on folate and vitamin B12 deficiencies. Food and Nutrition Bulletin, 29(2 Suppl), S238-S244 Retrieved from. (http://www.ncbi.nlm.nih.gov/pubmed/18709899).

de Meer, K, Smulders, Y. M. Dainty, J. R, Smith, D. E. C. Kok, R. M., Stehouwer, C. D. A Jakobs, C. (2005). [6S]5-methyltetrahydrofolate or folic acid supplementation and absorption and initial elimination of folate in young and middle-aged adults. European Journal of Clinical Nutrition, 59(12), 1409-1416 (http://doi.org/10.1038/sj.ejcn. 1602254).

Draget, K. I., \& Taylor, C. (2011). Chemical, physical and biological properties of alginates and their biomedical implications. Food Hydrocolloids, 25(2), 251-256 (http://doi.org/ 10.1016/j.foodhyd.2009.10.007).

Engelen, L., Van Der Bilt, A., Schipper, M., \& Bosman, F. (2005). Oral size perception of particles: Effect of size, type, viscosity and method. Journal of Texture Studies, 36(4), 373-386 (http://doi.org/10.1111/j.1745-4603.2005.00022.x).

European Food Safety Authority (2014). Scientific opinion on dietary reference values for folate. EFSA Journal, 12(11), 1-59 (http://doi.org/10.2903/j.efsa.2014.3893).

Gao, C., Liu, M., Chen, J., \& Zhang, X. (2009). Preparation and controlled degradation of oxidized sodium alginate hydrogel. Polymer Degradation and Stability, 94(9), 1405-1410 (http://doi.org/10.1016/j.polymdegradstab.2009.05.011).

Gardiner, G. E., Casey, P. G., Casey, G., Brendan, P., Lawlor, P. G., Hill, C., ... Lynch, P. B. (2004). Relative ability of orally administered Lactobacillus murinus to predominate and persist in the porcine gastrointestinal tract. Applied and Environmental Microbiology, 70, 1895-1906 (http://doi.org/10.1128/AEM.70.4.1895).

Gazori, T., Khoshayand, M. R., Azizi, E., Yazdizade, P., Nomani, A., \& Haririan, I. (2009). Evaluation of alginate/chitosan nanoparticles as antisense delivery vector: Formulation, optimization and in vitro characterization. Carbohydrate Polymers, 77(3), 599-606 (http://doi.org/10.1016/j.carbpol.2009.02.019).

Gueimonde, M., \& Salminen, S. (2006). New methods for selecting and evaluating probiotics. Digestive and Liver Disease, 38(2), 242-247 (http://doi.org/10.1016/ S1590-8658(07)60003-6).

Heidebach, T., Först, P., \& Kulozik, U. (2012). Microencapsulation of probiotic cells for food applications. Critical Reviews in Food Science and Nutrition, 52(4), 291-311 (http://doi. org/10.1080/10408398.2010.499801)

Jacob, R. A. (2000). Folate, DNA methylation, and gene expression: Factors of nature and nurture. The American Journal of Clinical Nutrition, 72, 903-904.

Kamalian, N., Mirhosseini, H., Mustafa, S., \& Manap, M. Y. A. (2014). Effect of alginate and chitosan on viability and release behavior of bifidobacterium pseudocatenulatum G4 in simulated gastrointestinal fluid. Carbohydrate Polymers, 111, 700-706 (http://doi. org/10.1016/j.carbpol.2014.05.014).

Khanna, O., Moya, M. L., Opara, E. C., \& Brey, E. M. (2010). Synthesis of multilayered alginate microcapsules for the sustained release of fibroblast growth factor-1. Journal of Biomedical Materials Research. Part A, 95(2), 632-640 (http://doi.org/10.1002/jbm.a. 32883).

Klein, J., Stock, J., \& Vorlop, K. (1983). Microbiology and biotechnology pore size and properties of spherical Ca-alginate biocatalysts, 86-91.

Kleinberger, R. M., Burke, N. A. D., Dalnoki-Veress, K., \& Stöver, H. D. H. (2013). Systematic study of alginate-based microcapsules by micropipette aspiration and confocal 
fluorescence microscopy. Materials Science \& Engineering C, Materials for Biological Applications, 33(7), 4295-4304 (http://doi.org/10.1016/j.msec.2013.06.033).

Klingberg, T. D., \& Budde, B. B. (2006). The survival and persistence in the human gastrointestinal tract of five potential probiotic lactobacilli consumed as freeze-dried cultures or as probiotic sausage. International Journal of Food Microbiology, 109(1-2), 157-159 (http://doi.org/10.1016/j.jifoodmicro.2006.01.014).

Krasaekoopt, W., Bhandari, B., \& Deeth, H. C. (2006). Survival of probiotics encapsulated in chitosan-coated alginate beads in yoghurt from UHT- and conventionally treated milk during storage. LWT - Food Science and Technology, 39(2), 177-183 (http://doi. org/10.1016/j.lwt.2004.12.006).

Lawrie, G., Keen, I., Drew, B., Chandler-Temple, A., Rintoul, L., Fredericks, P., \& Grøndahl, L. (2007). Interactions between alginate and chitosan biopolymers characterized using FTIR and XPS. Biomacromolecules, 8(8), 2533-2541 (http://doi.org/10.1021/ bm070014y).

Madziva, H., Kailasapathy, K., \& Phillips, M. (2005). Alginate-pectin microcapsules as a potential for folic acid delivery in foods. Journal of Microencapsulation, 22(4), 343-351 (http://doi.org/10.1080/02652040500100931).

Marteau, P., \& Shanahan, F. (2003). Basic aspects and pharmacology of probiotics: An overview of pharmacokinetics, mechanisms of action and side-effects. Best Practice E Research Clinical Gastroenterology, 17(5), 725-740. http://dx.doi.org/10.1016/ S1521-6918(03)00055-6.

Meng, X., Pan, Q., Ding, Y., \& Jiang, L. (2014). Rapid determination of phospholipid content of vegetable oils by FTIR spectroscopy combined with partial least-square regression. Food Chemistry, 147, 272-278 (http://doi.org/10.1016/j.foodchem.2013.09.143).

Morris, M. C., \& Tangney, C. C. (2007). Is dietary intake of folate too low? Lancet, 369, $166-167$.

Oliveira, T. M. B. F., Barroso, M. F., Morais, S., Araújo, M., Freire, C., Lima-neto, P. D., ... Delerue-matos, C. (2014). Sensitive bi-enzymatic biosensor based on polyphenoloxidases - Gold nanoparticles - Chitosan hybrid fi lm - Graphene doped carbon paste electrode for carbamates detection. Bioelectrochemistry, 98, 20-29 (http://doi.org/10.1016/j.bioelechem.2014.02.003).

Orive, G., Tam, S. K., Pedraz, J. L., \& Hallé, J. -P. (2006). Biocompatibility of alginate-poly-Llysine microcapsules for cell therapy. Biomaterials, 27(20), 3691-3700 (http://doi. org/10.1016/j.biomaterials.2006.02.048).

Pérez-Masiá, R., López-Nicolás, R., Periago, M. J., Ros, G., Lagaron, J. M., \& López-Rubio, A (2015). Encapsulation of folic acid in food hydrocolloids through nanospray drying and electrospraying for nutraceutical applications. Food Chemistry, 168, 124-133 (http://doi.org/10.1016/j.foodchem.2014.07.051).

Pinheiro, A. C., Bourbon, A. I., Vicente, A. a., \& Quintas, M. A. C. (2013). Transport mechanism of macromolecules on hydrophilic bio-polymeric matrices - Diffusion of protein-based compounds from chitosan films. Journal of Food Engineering, 116(3), 633-638 (http://doi.org/10.1016/j.jfoodeng.2012.12.038).

Po, H. N., \& Senozan, N. M. (2001). The Henderson-Hasselbalch equation: Its history and limitations. Journal of Chemical Education, 78(11), 1499 (http://doi.org/10.1021/ ed078p1499).

Quong, D., Neufeld, R. J., Skjåk-Braek, G., \& Poncelet, D. (1998). External versus internal source of calcium during the gelation of alginate beads for DNA encapsulation. Biotechnology and Bioengineering, 57(4), 438-446 Retrieved from http://www.ncbi. nlm.nih.gov/pubmed/10099220

Rathore, S., Desai, P. M., Liew, C. V., Chan, L. W., \& Heng, P. W. S. (2013). Microencapsulation of microbial cells. Journal of Food Engineering, 116(2), 369-381 (http://doi.org/10. 1016/j.jfoodeng.2012.12.022)

Sarmento, B., Ribeiro, A., Veiga, F., Sampaio, P., Neufeld, R., \& Ferreira, D. (2007). Alginate/ chitosan nanoparticles are effective for oral insulin delivery. Pharmaceutical Research, 24(12), 2198-2206 (http://doi.org/10.1007/s11095-007-9367-4).

Sheu, T. Y., \& Marshall, R. T. (1993). Microentrapment of lactobacilli in calcium alginate gels. Journal of Food Science, 54(3), 557-561.

Shi, J., Alves, N. M., \& Mano, J. F. (2007a). Chitosan coated alginate beads containing poly(N-isopropylacrylamide) for dual-stimuli-responsive drug release. Journal of
Biomedical Materials Research. Part B, Applied Biomaterials, 83(2), 340-344 (http:// doi.org/10.1002/jbmb)

Shi, J., Alves, N. M., \& Mano, J. F. (2007). Chitosan coated alginate beads containing poly(N-isopropylacrylamide) for dual-stimuli-responsive drug release. Journal of Biomedical Materials Research. Part B, Applied Biomaterials, 83(2), 340-344 (http:// doi.org/10.1002/jbmb).

Smidsrd, O., \& Skjak-Brae, G. (1990). Alginate as immobilization matrix for cells. Tibtech 8(March), 71-78.

Sriamornsak, P., Thirawong, N., \& Korkerd, K. (2007). Swelling, erosion and release behavior of alginate-based matrix tablets. European Journal of Pharmaceutics and Biopharmaceutics, 66(3), 435-450 (http://doi.org/10.1016/j.ejpb.2006.12.003).

Stolzenberg-solomon, R. Z., Chang, S., Leitzmann, M. F., Johnson, K. A., Johnson, C., Buys, S S., ... Al, S. E. T. (2006). Folate intake, alcohol use, and postmenopausal breast cancer risk in the prostate, lung, colorectal, and ovarian cancer screening1. (pp. 895-904), 895-904.

Sybesma, W., Starrenburg, M., Tijsseling, L., Hoefnagel, M. H. N., \& Hugenholtz, J. (2003) Effects of cultivation conditions on folate production by lactic acid bacteria. Applied and Environmental Microbiology, 69(8), 4542-4548 (http://doi.org/10.1128/AEM.69. 8.4542).

Takeuchi, H., Thongborisute, J., Matsui, Y., Sugihara, H., Yamamoto, H., \& Kawashima, Y. (2005). Novel mucoadhesion tests for polymers and polymer-coated particles to design optimal mucoadhesive drug delivery systems. Advanced Drug Delivery Reviews, 57(11), 1583-1594 (http://doi.org/10.1016/j.addr.2005.07.008).

Tam, S. K., Bilodeau, S., Dusseault, J., Langlois, G., Hallé, J. -P., \& Yahia, L. H. (2011). Biocompatibility and physicochemical characteristics of alginate-polycation microcapsules. Acta Biomaterialia, 7(4), 1683-1692 (http://doi.org/10.1016/j.actbio.2010.12.006).

Tam, S. K., Dusseault, J., Polizu, S., Ménard, M., Hallé, J. P., \& Yahia, L. (2005a). Physicochemical model of alginate-poly-L-lysine microcapsules defined at the micrometric/ nanometric scale using ATR-FTIR, XPS, and ToF-SIMS. Biomaterials, 26, 6950-6961 (http://doi.org/10.1016/j.biomaterials.2005.05.007).

Tam, S. K., Dusseault, J., Polizu, S., Ménard, M., Hallé, J. -P., \& Yahia, L. (2005b). Physicochemical model of alginate-poly-L-lysine microcapsules defined at the micrometric/ nanometric scale using ATR-FTIR, XPS, and ToF-SIMS. Biomaterials, 26(34), 6950-6961 (http://doi.org/10.1016/j.biomaterials.2005.05.007).

Tanaka, H., \& Matsumura, M. (1983). Diffusion characteristics of substrates in Ca-alginate gel beads.

Tang, Z., Wang, Y., Podsiadlo, P., \& Kotov, N. a. (2006). Biomedical applications of layer-bylayer assembly: From biomimetics to tissue engineering. Advanced Materials, 18(24), 3203-3224 (http://doi.org/10.1002/adma.200600113).

Thu, B., Bruheim, P., Espevik, T., \& Skj, G. (1996). Alginate polycation microcapsules I. Interaction between alginate and polycation. Biomaterials, 17(10), 1031-1040.

Ulrich, C. M., \& Potter, J. D. (2006). Folate supplementation: Too much of a good thing? Cancer Epidemiology, Biomarkers \& Prevention. A Publication of the American Association for Cancer Research. Cosponsored by the American Society of Preventive Oncology, 15(2), 189-193 (http://doi.org/10.1158/1055-9965.EPI-152CO).

Vlachos, N., Skopelitis, Y., Psaroudaki, M., Konstantinidou, V., Chatzilazarou, A., \& Tegou, E. (2006). Applications of Fourier transform-infrared spectroscopy to edible oils Analytica Chimica Acta, 573-574, 459-465 (http://doi.org/10.1016/j.aca.2006.05.034).

Yan, Y., Björnmalm, M., \& Caruso, F. (2014). Assembly of layer-by-layer particles and their interactions with biological systems. Chemistry of Materials, 26(1), 452-460 (http:// doi.org/10.1021/cm402126n).

Yoshida, T., \& Nagasawa, T. (2003). Epsilon-poly-L-lysine: Microbial production, biodegradation and application potential. Applied Microbiology and Biotechnology, 62(1), 21-26 (http://doi.org/10.1007/s00253-003-1312-9).

Zhao, Q., Han, B., Wang, Z., Gao, C., Peng, C., \& Shen, J. C. (2007). Hollow chitosan-alginate multilayer microcapsules as drug delivery vehicle: doxorubicin loading and in vitro and in vivo studies. Nanomedicine: Nanotechnology, Biology, and Medicine, 3(1), 63-74 (http://doi.org/10.1016/j.nano.2006.11.007). 